\title{
openheart Long-term outcomes after treatment of in-stent restenosis using the Absorb everolimus-eluting bioresorbable scaffold
}

\author{
Mehdi Madanchi (D) , Giacomo Maria Cioffi, Adrian Attinger-Toller, \\ Mathias Wolfrum, Federico Moccetti, Thomas Seiler, Luca Vercelli, Philipp Burkart, \\ Stefan Toggweiler, Richard Kobza, Matthias Bossard, Florim Cuculi
}

To cite: Madanchi M, Cioffi GM, Attinger-Toller A, et al. Longterm outcomes after treatment of in-stent restenosis using the Absorb everolimus-eluting bioresorbable scaffold. Open Heart 2021;8:e001776. doi:10.1136/ openhrt-2021-001776

MM and GMC contributed equally.

MM and GMC are joint first authors.

$\mathrm{MB}$ and $\mathrm{FC}$ are joint senior authors.

Received 9 July 2021

Accepted 27 August 2021
Check for updates

(c) Author(s) (or their employer(s)) 2021. Re-use permitted under CC BY-NC. No commercial re-use. See rights and permissions. Published by BMJ.

Department of Cardiology, Luzerner Kantonsspital, Luzern, Switzerland

Correspondence to

Dr Florim Cuculi; florim.cuculi@ luks.ch

\section{ABSTRACT}

Background Early studies evaluating the performance of bioresorbable scaffold (BRS) Absorb in in-stent restenosis (ISR) lesions indicated promising short-term to mid-term outcomes.

Aims To evaluate long-term outcomes (up to 5 years) of patients with ISR treated with the Absorb BRS.

Methods We did an observational analysis of long-term outcomes of patients treated for ISR using the Absorb BRS (Abbott Vascular, Santa Clara, California, USA) between 2013 and 2016 at the Heart Centre Luzern. The main outcomes included a device-oriented composite endpoint (DOCE), defined as composite of cardiac death, target vessel (TV) myocardial infarction and TV revascularisation, target lesion revascularisation and scaffold thrombosis (ScT).

Results Overall, 118 ISR lesions were treated using totally 131 BRS among 89 patients and $31(35 \%)$ presented with an acute coronary syndrome. The median follow-up time was 66.3 (IQR 52.3-77) months. A DOCE had occurred in $17 \%$ at 1 year, $27 \%$ at 2 years and $40 \%$ at 5 years of all patients treated for ISR using Absorb. ScTs were observed in six $(8.4 \%)$ of the cohort at 5 years.

Conclusions Treatment of ISR using the everolimuseluting BRS Absorb resulted in high rates of DOCE at 5 years. Interestingly, while event rates were low in the first year, there was a massive increase of DOCE between 1 and 5 years after scaffold implantation. With respect to its complexity, involving also a more unpredictable vascular healing process, current and future BRS should be used very restrictively for the treatment of ISR.

\section{INTRODUCTION}

Despite the latest advancements in percutaneous coronary interventions (PCI), including novel drug-eluting stent (DES) platforms and improved implantation techniques, in-stent restenosis (ISR) remains a commonly encountered adverse outcomes among patients with chronic coronary syndrome (CCS). ${ }^{1}$ Whereas ISR rates up to $30 \%$ had been observed with bare metal

\section{Key questions}

What is already known about this subject?

- The introduction of bioresorbable scaffolds (BRSs), particularly the Absorb BRS, for treatment of coronary artery disease was received with a lot of enthusiasm and initial trial results appeared promising. Those devices were expected to provide radial strength in the early phase and dissolve over time, which results in lumen gain. However, multiple longterm follow-up studies indicated high rates of target lesion failure and scaffold thrombosis when compared with contemporary metallic stents. BRSs have also being used for treatment of in-stent restenosis (ISR). Nevertheless, long-term outcomes have not been systematically assessed yet.

What does this study add?

- To the best of our knowledge, this is first study reporting long-term outcomes of patients with ISR treated with the Absorb BRS. Treatment of ISR using the everolimus-eluting Absorb resulted in high rates of adverse outcomes at 5 years, including target vessel revascularisation. Interestingly, while event rates were low in the first year, there was a remarkable increase of device related adverse outcomes between 1 and 5 years after scaffold implantation.

How might this impact on clinical practice?

- Besides providing insights about long-term clinical outcomes of patients with ISR treated with the Absorb, our data also offer results additional aspects for management of patients presenting with ISR in the future, since ISR remains a clinical challenge and the optimal management is still under debate. Furthermore, our paper raises awareness on the fact that early promising results can be misleading, and the non-critical introduction of new technologies could be harmful for certain patients.

stents (BMS), more recent studies with contemporary DES still reported ISR ranging from $5 \%$ to $10 \% .^{2-4}$ 
To date, the optimal management of ISR is still under debate and represents a therapeutic challenge. Multiple approaches have been tested, including second and thirdgeneration DES, drug-coated balloons (DCB), rotational atherectomy and brachytherapy. ${ }^{56}$ The latest guidelines of the European Society of Cardiology recommend either implantation of a contemporary DES (preferably an everolimus-eluting stent) or use of DCB for BMSISR, whereas DES-related ISR should be managed with DES. Furthermore, the use of DCB has shown favourable outcomes, especially in small-sized vessels, bifurcations, BMS-ISR and when more than two stent layers are already present in the vessel. ${ }^{78}$

Early after its market introduction, the everolimuseluting bioresorbable scaffold (BRS) Absorb (Abbott Vascular, Santa Clara, California,USA) has been considered as a promising treatment option for ISR, mainly because of the fact of being integrated in the vessel wall with time, which may avoid the so called 'onion-skin phenomenon' (implantation of several layers of metallic stent in the same lesion), mitigating the risk for late lumen loss and improved re-endothelialisation. ${ }^{9} 10$

We published our early experience (6-12 months results) with the Absorb BRS for ISR treatment, which in fact was quite promising, including a very low incidence of target vessel revascularisation (TVR) and no scaffold thrombosis $(\mathrm{ScT}){ }^{11}$

Hereby, we now present the very long-term follow-up data (up to 5 years) of all patients that had been treated for clinically relevant ISR using the Absorb BRS at our institution.

\section{METHODS}

All patients treated with the Absorb BRS between September 2013 and December 2016 had been included in an ongoing retrospective PCI registry (L-CAD registry, BASEC ID 2019-01067). For this study, we analysed data from all patients treated for ISR with at least one Absorb BRS. Of note, 25 patients had been included in the prospective, randomised with ABSORB-ISR study (ClinicalTrials.gov identifier: NCT02474485). The study took place at the Luzerner Kantonsspital (Lucerne, Switzerland), which represents the tertiary cardiology facility for the central part of Switzerland, with an PCI volume of approximately 1700 cases/year.

The final decision whether to use a DCB, DES or BRS for treatment of ISR remained at the discretion of the interventional cardiologist. Patients with symptomatic, stable CCS and those with acute coronary syndrome (ACS) were eligible for the study. Of note, the Absorb BRS was not used in the following settings: (1) patients with a history of a previous stent thrombosis, (2) saphenous or arterial graft lesions, (3) vessel diameters $<2.5$ and $>4.0 \mathrm{~mm}$, (4) bifurcation lesions requiring a two-stent strategy and (5) and residual stenosis $>50 \%$ after predilatation.

To achieve maximum luminal gain, we routinely use non-compliant (NC) balloons for lesion preparation. ${ }^{12}$ In the context of ISR, we mainly use the ultra high-pressure NC balloons (OPN NC, SIS Medical, Winterthur, Switzerland; rated burst pressure (RBP) at $35 \mathrm{~atm}$ ) and whenever needed intravascular imaging (optical coherence tomography, OCT, Dragonfly Abbott Vascular). All lesions were predilated using either the BEO NC (SIS Medical, Winterthur, Switzerland; RBP $24 \mathrm{~atm}$ ) or OPN NC balloons. The Absorb BRS was implanted at 12-16 atm with gradually increasing pressure (as recommended by IFU) with the intention of completely covering the diseased segment. If necessary, postdilatation was performed using either a regular NC balloon or an OPN NC.

All angiograms were reviewed by two experienced physicians (MB and FC). The same applied for the OCT runs. The angiographic pattern of ISR was classified according to Mehran et $a l^{13}$ as focal (1, ISR $<10 \mathrm{~mm}$ ), diffuse (2, ISR $>10 \mathrm{~mm}$ within the stent), proliferative (3, ISR $>10 \mathrm{~mm}$ extending outside the stent) and occlusive (4, totally occluded ISR). Quantitative coronary angiography (QCA) analysis was performed before (if the vessel was not completely occluded) and after BRS implantation using Xcelera software, V.3.2.1 (Philips Healthcare, Best, The Netherlands). Measurements were taken on cine angiograms recorded after intracoronary nitroglycerine administration. Baseline measurements were taken with the single worst view projection and repeated in the same projection. The contrast-filled non-tapered catheter tip was used for calibration. In selected cases OCT was used to guide BRS implantation.

PCI was performed using heparin (70-100 units/kg body weight) (target activated clotting time (ACT) $>230$ 250 s during PCI). Eptifibatide was administered only in selected patients, mainly in patients presenting with an ACS. Patients with stable CCS were discharged on aspirin and clopidogrel, while those with ACS received ticagrelor or prasugrel in addition to aspirin. Dual antiplatelet therapy was recommended for 12 months.

Follow-up was performed via telephone, clinical visits and/or chart reviewing at 6 months, 1 year, 2 years and up to 5 years after scaffold implantation. Patients with reoccurrence of angina underwent invasive coronary angiography. The patients who had been enrolled in the ABSRORB-ISR trial underwent repeat coronary angiography 9 months after scaffold implantation as per study protocol.

The primary outcome was a device-oriented composite endpoint (DOCE) defined as composite of cardiac death, target vessel myocardial infarction (TV-MI) and TVR. The secondary endpoints included target lesion revascularisation (TLR) and probable or definite ScT according to the criteria of the Academic Research Consortium (ARC). ${ }^{14}$

Categorical variables are displayed as absolute numbers and percentages, and continuous variables are presented as means $( \pm \mathrm{SDs})$ or medians (IQRs), as appropriate. Outcomes over time were plotted using Kaplan-Meier curves. Follow-up of the patients were censored at 5 years since the index procedure. A $\mathrm{p} \leq 0.05$ was considered as statistically significant. $\mathrm{P}$ values were calculated using 


\begin{tabular}{|c|c|}
\hline Baseline characteristics & No of patients $(n=89)$ \\
\hline Age (years) & $66.2 \pm 9.8$ \\
\hline Males (\%) & $78(88)$ \\
\hline Median follow-up time (months) & $66.3(52.3 ; 77)$ \\
\hline \multicolumn{2}{|l|}{ Presentation (\%) } \\
\hline Chronic coronary syndrome & $58(65)$ \\
\hline Acute coronary syndrome & $31(35)$ \\
\hline \multicolumn{2}{|l|}{ STEMI } \\
\hline \multicolumn{2}{|l|}{ NSTEMI } \\
\hline \multicolumn{2}{|l|}{ Cardiovascular risk factors (\%) } \\
\hline Arterial hypertension (\%) & $67(75)$ \\
\hline Diabetes mellitus (\%) & $24(27)$ \\
\hline Dyslipidaemia (\%) & $70(79)$ \\
\hline Current smoking (\%) & $49(55)$ \\
\hline Previous MI (\%) & $42(47)$ \\
\hline Previous CABG (\%) & $9(10)$ \\
\hline \multicolumn{2}{|l|}{ Antithrombotics (\%) } \\
\hline Aspirin & $88(99)$ \\
\hline Clopidogrel & $59(66)$ \\
\hline Ticagrelor & $14(16)$ \\
\hline Prasugrel & $16(18)$ \\
\hline Oral anticoagulant & $3(3.4)$ \\
\hline \multicolumn{2}{|l|}{ Access (\%) } \\
\hline Radial & $74(83)$ \\
\hline Femoral & $15(17)$ \\
\hline
\end{tabular}

Data are mean (SD), median (IQR) or number (percentage), as appropriate.

CABG, coronary artery bypass grafting; MI, myocardial infarction; NSTEMI, non-ST segment elevation myocardial infarction; STEMI, ST-segment elevation myocardial infarction.

pared t-tests and Wilcoxon rank-sum test, where applicable. The analyses were conducted using STATA V.16.

\section{RESULTS}

In total, 89 patients were included in this study and 119 lesions were treated. The baseline characteristics are summarised in table 1 . The majority of patients were male $(88 \%)$ with a mean age of $66.2 \pm 9.8$ years. Most of the patients presented with a CCS $58(65 \%)$ and 42 patients $(47 \%)$ had a previous MI.

Detailed procedural and angiographic information is provided in table 2 . The most commonly treated vessel represented the right coronary artery $(60$ cases $(51 \%))$. With respect to the ISR characteristics, $47(40 \%)$ of the lesions represented proliferative (3) or occlusive (4) ISR, $61(52 \%)$ showed a moderate to severe calcification and $21(18 \%)$ were chronic total occlusions. All the lesions were predilated using NC balloons at high pressure $(26.8 \pm 1.3 \mathrm{~mm} \mathrm{Hg})$. A total of 131 scaffolds were implanted at mean deployment pressure of $14.7 \pm 0.4 \mathrm{~mm}$
Table 2 Lesion characteristics of the study population

\begin{tabular}{|ll|}
\hline Lesion characteristics & No of lesions (n=118) \\
\hline $\begin{array}{l}\text { Vessels treated (\%) } \\
\text { Left anterior descending }\end{array}$ & $31(26)$ \\
\hline Left circumflex & $27(23)$ \\
\hline Right coronary artery & $60(51)$ \\
\hline $\begin{array}{l}\text { Type of in-stent restenosis (\%) } \\
\text { (1)Focal }\end{array}$ & $32(27)$ \\
\hline (2) Diffuse & $39(33)$ \\
\hline (3) Proliferative & $28(24)$ \\
\hline (4) Occlusive & $19(16)$ \\
\hline More than one scaffold per lesion (\%) & $27(30)$ \\
\hline Aorto-ostial lesions (\%) & $2(1.7)$ \\
\hline Chronic total occlusions (\%) & $21(18)$ \\
\hline Moderate to severe calcification (\%) & $61(52)$ \\
\hline Type of restenosed stent (\%) & \\
\hline BMS & $7(6)$ \\
\hline First generation DES & $24(20)$ \\
\hline Second generation DES & $87(74)$ \\
\hline Layers of stent (\%) & \\
\hline One & $86(73)$ \\
\hline Two or more & $32(27)$ \\
\hline History of DCB treatment (\%) & $10(8.5)$ \\
\hline OCT guidance (\%) & $32(27)$ \\
\hline Lesion preparation (mm, mean) & \\
\hline Pre-dilatation balloon diameter & $3.0 \pm 0.07$ \\
\hline Pre-dilatation pressure & $26.8 \pm 1.3$ \\
\hline Regular NC balloon (\%) & $31(26)$ \\
\hline Ultra-high pressure NC balloon (\%) & $89(75)$ \\
\hline Total scaffolds implanted & 131 \\
\hline Absorb BRS characteristics (mm, mean) & \\
\hline Scaffold diameter & $3.1 \pm 0.07$ \\
\hline Scaffold length & $24 \pm 1$ \\
\hline Scaffold deployment pressure (atm, \\
mean) & $14.7 \pm 0.4$ \\
\hline Post-dilatation (\%) & $56(47)$ \\
\hline Post-dilatation pressure (atm) & $27.7 \pm 1.9$ \\
\hline Datar & \\
\hline
\end{tabular}

Data are mean (SD) or number (percentage), as appropriate. BMS, bare metal stents; BRS, bioresorbable scaffold; DCB, drug coated balloon; DES, drug eluting stents; NC, non-compliant; OCT, optical coherence tomography.

Hg. Postdilatation was performed in $58(49 \%)$ lesions at a mean pressure of $27.7 \pm 1.9 \mathrm{~mm} \mathrm{Hg}$. OCT guidance was used in $32(27 \%)$ lesions.

The QCA analyses are illustrated in table 3. The mean lesion length was $22.1 \pm 1.9 \mathrm{~mm}$, and the minimal lumen diameter significantly increased from $1.02 \pm 0.1 \mathrm{~mm}$ to $2.65 \pm 0.09 \mathrm{~mm}$ after BRS implantation $(\mathrm{p}<0.001)$. 
Table 3 Quantitative coronary angiography (QCA) analysis of the study population

\begin{tabular}{llll}
\hline QCA & $\begin{array}{l}\text { Before } \\
\text { BRS }\end{array}$ & $\begin{array}{l}\text { After } \\
\text { BRS }\end{array}$ & $\begin{array}{l}\text { P } \\
\text { value* }\end{array}$ \\
\hline Lesion length $(\mathrm{mm})$ & $22.1 \pm 1.9$ & - & - \\
\hline Minimal lumen diameter $(\mathrm{mm})$ & $1 \pm 0.5$ & $2.6 \pm 0.5$ & $<0.001$ \\
Reference vessel diameter $(\mathrm{mm})$ & $3.2 \pm 0.5$ & $3.4 \pm 0.4$ & $<0.001$ \\
Diameter stenosis $(\%)$ & $73.2 \pm 17$ & $18.4 \pm 10.4$ & $<0.001$ \\
\hline
\end{tabular}

Data are mean (SD).

${ }^{*} P$ values were based on Student's t-tests.

BRS, bioresorbable scaffold.

The median follow-up time was 66.3 (IQR 52.3-77) months. Overall, the primary endpoint DOCE had occurred in $17 \%, 27 \%$, and $40 \%$ of all patients at 1 year, 2 years and 5 years respectively (highlighted in table 4 and figure 1A). Regarding the rate of TV-MI, this was $2.3 \%$ at 1 year, $4.7 \%$ at 2 years and of $10.0 \%$ at 5 years, as also illustrated in the figure 1B Two typical patterns of target lesion failure after BRS implantation encountered during follow-up are displayed in figure 2. The rate of ScT was low at 1 year (one case, $1.1 \%$ ), but steadily increased over time (at 5 years $8.4 \%$ of all cases), whereas the majority of events occurred between the second and fifth year after scaffold implantation. Of note, a case of very late ScT was observed 41 months after implantation (case vignette, figure 3). A total of 14 (20\%) patients had died at 5 years, with cardiac death accounting for $2(3 \%)$ of the patients.

When comparing the clinical and angiographic characteristics of patients with DOCE versus no-DOCE after ISR treatment using the BRS Absorb, we found that a number of patients with diabetes and occlusive ISR were significantly higher among those presenting with an adverse outcome during the follow-up, see table 5 .

\section{DISCUSSION}

Theoretically, BRS could represent an ideal solution for treatment of ISR, since they offer a prolonged release of an antiproliferative drug and the scaffolding properties provide radial strength in the acute phase resulting in more acute luminal gain. Additionally, the expected scaffold dissolution was supposed to lead to less local chronic inflammation compared with a permanent metal implant, thus reducing the risk of neointimal tissue growth, neoatherosclerosis and thrombosis ${ }^{1516}$

However and in line with some of the major trials evaluating the BRS Absorb for treatment of native coronary lesions, our study investigating long-term outcomes after treatment of ISR using this everolimus-eluting BRS revealed a worrying increase of DOCE between 1 and 5 years after scaffold implantation, reaching $40 \%$ at 5 years follow-up. To the best of our knowledge, this is the first study reporting very long-term follow-up data after treatment of ISR with the Absorb BRS.

Our early data implicated promising results after 6 months (TVR rate $4.6 \%$ ) but an increase in TVR reaching $18.4 \%$ at 12 months. ${ }^{11}$ This was initially considered acceptable given the complexity of coronary artery disease in the treated population and a prospective randomised trial comparing the Absorb BRS versus the DCB SeQuent Please NEO was initiated. ${ }^{17}$ We observed a steep increase in DOCE between 1 and 5 years, whereas the main contributor represented TVR due to recurrent

\begin{tabular}{|c|c|c|c|c|}
\hline Clinical outcomes & 6 months & 1 year & 2 years & 5 years \\
\hline Patients at follow-up (\%) & $88 / 89$ (99) & $87 / 89(98)$ & $76 / 89(85)$ & $71 / 89(80)$ \\
\hline \multicolumn{5}{|l|}{ Primary endpoint (\%) } \\
\hline DOCE & $6(6.8)$ & $14(16)$ & $22(29)$ & $33(46)$ \\
\hline TVR & $6(6.8)$ & $15(17)$ & $23(30)$ & $34(48)$ \\
\hline All TVR ${ }^{\star}$ & 6 & 16 & 26 & 49 \\
\hline TV-MI & $2(2.3)$ & $2(2.3)$ & $3(3.9)$ & $8(11)$ \\
\hline All TV-MI* & 2 & 2 & 3 & 10 \\
\hline Cardiac death & 0 & 0 & 0 & $2(2.8)$ \\
\hline \multicolumn{5}{|l|}{ Secondary endpoints (\%) } \\
\hline Definite or probable ScT & $1(1.1)$ & $1(1.1)$ & $3(3.9)$ & $6(8.4)$ \\
\hline TLR & $6(6.8)$ & $15(17)$ & $20(26)$ & $31(44)$ \\
\hline All TLR ${ }^{\star}$ & 6 & 16 & 23 & 46 \\
\hline All-cause death & $1(1.1)$ & $2(2.3)$ & $6(7.9)$ & $14(20)$ \\
\hline CABG & $0(0)$ & $0(0)$ & $2(2.6)$ & $5(7)$ \\
\hline
\end{tabular}

Data are presented as number (percentage).

${ }^{*}$ Cumulative events (one or more events per patient possible).

CABG, coronary artery bypass grafting; DOCE, device-oriented composite endpoint; ScT, scaffold thrombosis; TLR, target lesion revascularisation; TV-MI, target vessel myocardial infarction; TVR, target vessel revascularisation. 
A

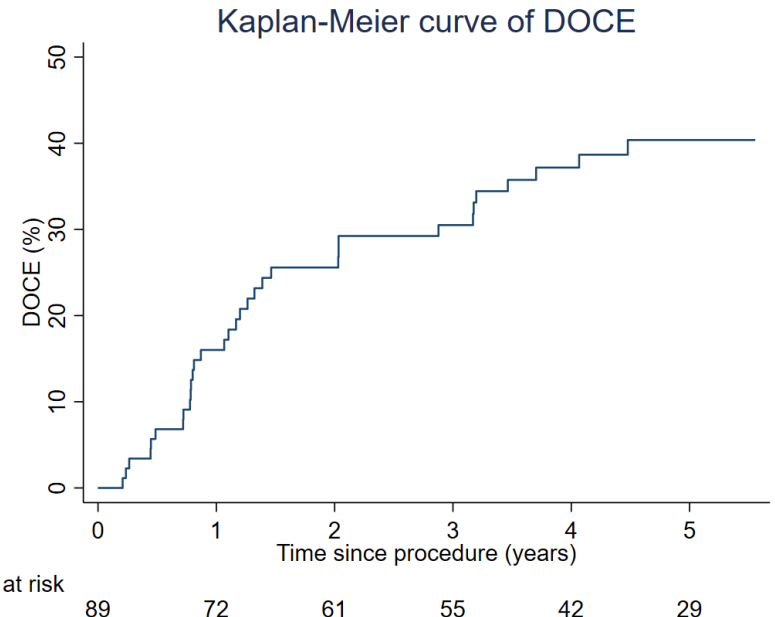

B
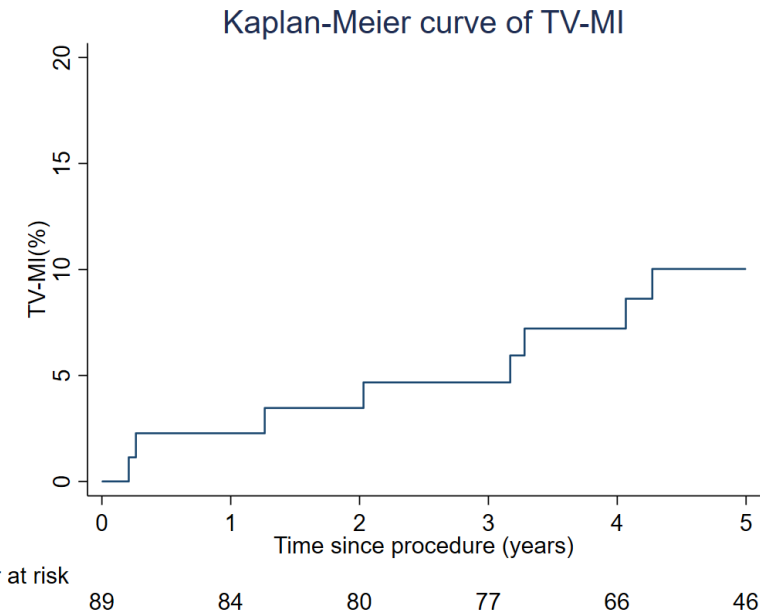

Figure 1 Kaplan-Meier estimate of device-oriented composite outcome (DOCE) and of target vessel myocardial infarction (TVMI): (A) graph showing the number of DOCE and (B) of TV-MI over time.

ISR. Moreover, a relevant number of patients experienced ScT. Interestingly, ScT started occurring most frequently after 2 years and still occurred up to 5 years postprocedure with the cumulative rate of ScT at 5 years reaching $8.4 \%$, which may implicate a a persistently elevated risk for acute vessel closure due thrombotic complications (very late ScT). By comparison, large, randomised studies of ISR lesions treated with DES report TLR rates ranging from $12 \%$ to $16 \%$ at 12 months and of $33 \%$ between 3 and 5 years, with most thrombotic complications occurring between 0 and 3 years. ${ }^{18-22}$

Different structural, procedural and clinical factors could explain the failure of the Absorb BRS in the context of ISR. First, the relatively thick struts $(150 \mu \mathrm{m})$ and the material itself (polymer poly-L-lactic acid) have been associated with an enhanced medial layer injury

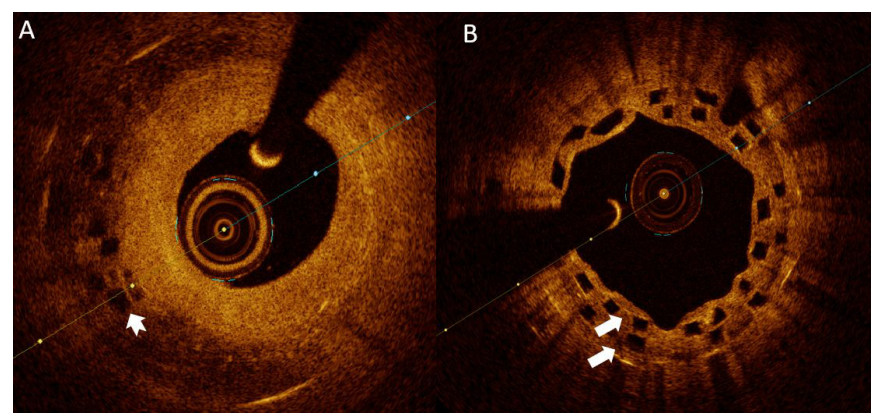

Figure 2 Optical coherence tomography (OCT) frames showing different scaffold failure mechanisms: (A) OCT frame of the proximal RCA showing considerable neointimal formation. The filling defects (arrowheads) indicate incomplete dissolution of the BRS scaffold 6.5 years after implantation. (B) OCT frame of the mid to distal right coronary artery (RCA) depicting overlapping scaffolds (arrows) 9 months post-treatment of a long in-stent restenosis lesion with two scaffolds. The precise positioning of the scaffolds was challenging. In this case, scaffold overlap resulted in large luminal loss. BRS, bioresorbable scaffold. and inflammation and consequently higher risk of neointimal hyperplasia. ${ }^{23-27}$ Of note, we encountered a case of incomplete scaffold dissolution even 6 years after

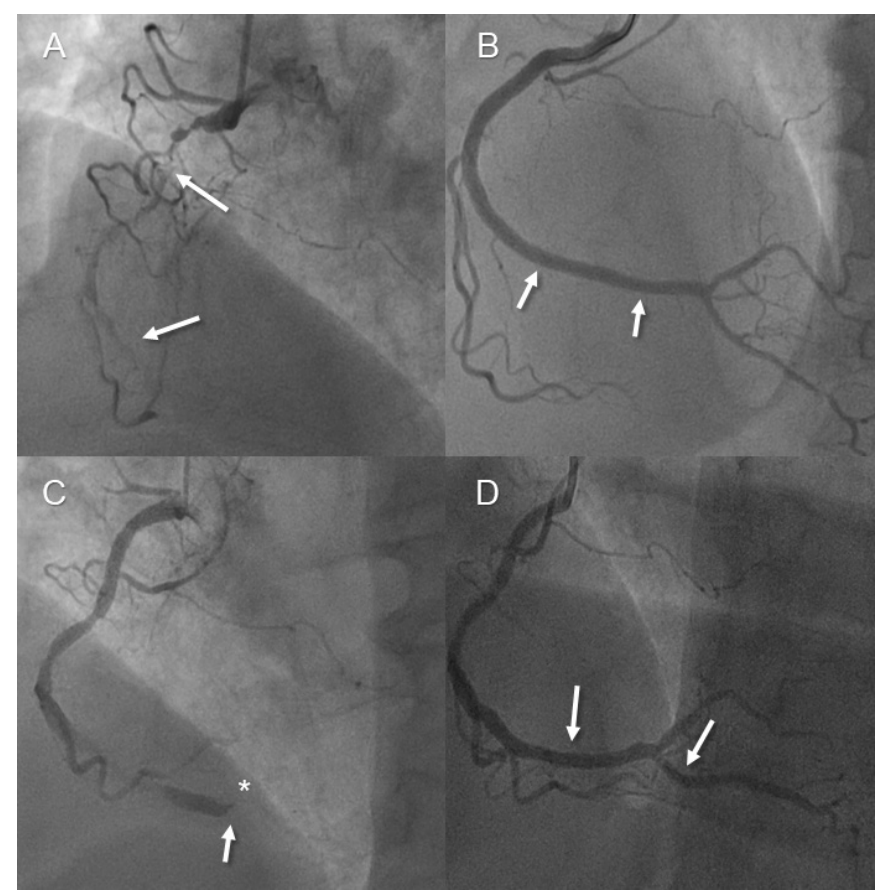

Figure 3 Case vignette of a patient in their 60s, presenting with target lesion failure (scaffold thrombosis) 41 months after implantation of an Absorb bioresorbable vascular scaffold (BRS) for in-stent restenosis (ISR) to the right coronary artery (RCA). (A) Initial angiogram indicating severe and long ISR of the RCA (arrow); (B) final result after ISR treatment using an everolimus-eluting Xience stent and two Absorb BRS (arrows); (C) angiogram at follow-up (after 41 months) - target lesion failure due to very late scaffold/ stent thrombosis (TIMI 0 flow) $\left(^{*}\right)$ at the level of the distal RCA bifurcation (arrow) and (D) final angiographic result after primary $\mathrm{PCl}$ using two everolimus-eluting Xience stents (with TIMI three flow) (arrows). PCI, percutaneous coronary interventions. TIMI, thrombolysis In myocardial infarction. 
Table 5 Comparison of the baseline and angiographic characteristics according to the occurrence of any DOCE versus no DOCE

\begin{tabular}{|c|c|c|c|}
\hline & $\begin{array}{l}\text { No DOCE } \\
(n=56)\end{array}$ & $\begin{array}{l}\text { DOCE } \\
(n=33)\end{array}$ & $\begin{array}{l}\text { P } \\
\text { value* }\end{array}$ \\
\hline Age (years) & $64.5 \pm 9.8$ & $67.1 \pm 9.9$ & ns \\
\hline Males (\%) & $51(91)$ & $27(82)$ & ns \\
\hline \multicolumn{4}{|l|}{ Presentation (\%) } \\
\hline Chronic coronary syndrome & $37(66)$ & $21(64)$ & ns \\
\hline Acute coronary syndrome & $19(34)$ & $12(36)$ & ns \\
\hline \multicolumn{4}{|l|}{ Cardiovascular risk factors (\%) } \\
\hline Arterial hypertension (\%) & $40(71)$ & $27(82)$ & ns \\
\hline Diabetes mellitus (\%) & $9(16)$ & $15(45)$ & 0.02 \\
\hline Dyslipidaemia (\%) & $41(73)$ & $29(88)$ & ns \\
\hline Current smoking (\%) & $29(52)$ & $20(61)$ & ns \\
\hline Previous Ml (\%) & $29(52)$ & $13(40)$ & ns \\
\hline Previous CABG (\%) & $5(9)$ & $7(12)$ & ns \\
\hline \multicolumn{4}{|l|}{ Antithrombotics (\%) } \\
\hline Aspirin & $55(98)$ & $33(100)$ & ns \\
\hline Clopidogrel & $36(64)$ & $23(70)$ & ns \\
\hline Ticagrelor & $8(14)$ & $6(18)$ & ns \\
\hline Prasugrel & $7(12)$ & $8(24)$ & ns \\
\hline Oral anticoagulant & $3(3.4)$ & $0(0.0)$ & - \\
\hline \multicolumn{4}{|l|}{ Access (\%) } \\
\hline Radial & $45(80)$ & $29(88)$ & ns \\
\hline Femoral & $11(20)$ & $4(12)$ & ns \\
\hline \multicolumn{4}{|l|}{ Culprit vessel (\%) } \\
\hline Left anterior descending & $14(25)$ & $10(30)$ & ns \\
\hline Left circumflex & $15(27)$ & $5(15)$ & ns \\
\hline Right coronary artery & $26(46)$ & $19(58)$ & ns \\
\hline \multicolumn{4}{|l|}{ Type of in-stent restenosis (\%) } \\
\hline (1)Focal & $17(30)$ & $7(21)$ & ns \\
\hline (2) Diffuse & $20(36)$ & $11(33)$ & ns \\
\hline (3) Proliferative & $12(21)$ & $7(21)$ & ns \\
\hline (4) Occlusive & $3(7)$ & $8(24)$ & 0.02 \\
\hline
\end{tabular}

Data are mean (SD) or number (percentage), as appropriate. ${ }^{*} P$ values were based on Student's t-tests, Mann-Whitney $U$ tests, as appropriate.

CABG, coronary artery bypass; DOCE, device-oriented composite endpoint; MI, myocardial infarction; ns, not significant.

implantation (figure 2A). Second, although intravascular imaging was used in almost one-third of the patients, we need to acknowledge that in the early implementation phase of the Absorb BRS, postdilatation was not a routine procedure, due to concerns on hampering the scaffold's integrity by aggressive postdilatation. This might have left some scaffolds somewhat underexpanded. However, the relatively low event rate in the first 6 months indirectly indicate a sufficient scaffold expansion, which also argues against a mechanical reason for DOCE. In addition, the late increase of events, consistent with the steep increase between 1 and 2 years as depicted in figure 1A, is probably linked to the early scaffold dissolution, which begin around 9-12 months after implantation and ultimately lead to loss of radial strength and vessel recoil. ${ }^{28}$ This finding could also be observed in large BRS trials in native vessels, which demonstrated low event rates in the first year post-implantation but high rates thereafter. ${ }^{10} 212930$ Furthermore, scaffold overlap, as seen in one-third of our patients, may have further contributed to luminal loss (figure 2B). Finally, our study population received DAPT for the maximum of 12 months, but a prolonged DAPT regimen (up to 3 years postimplantation) could have resulted in less ScT. ${ }^{22} 3132$

We are convinced that our study and the lessons learnt from the early BRS experience have important clinical implications. Although the Absorb BRS is not used anymore in clinical practice, other devices are still being used and developed. ${ }^{24}$ BRSs do not seem to hold the theoretical promise of a efficient antiproliferative drug carrier with self-dissolving properties resulting in late luminal gain.

Whether other scaffold platforms and materials will result in better clinical outcomes remains to be proven. In our opinion, we should apply the knowledge acquired and focus on two important features when using BRS in the future. First, the meticulous use of intravascular imaging, in order to achieve maximal luminal gain, and second the avoidance of very complex lesions (including ISR and highly calcified lesions). Early promising results can be misleading, and the non-critical introduction of new technologies could be potentially harmful for certain groups of patients.

There are several limitations to our study. First, it is a single-centre study with observational nature, thus generalisability is limited. Second, it comprises a relatively small cohort. Third, the cohort is composed of two study populations with different follow-up strategies. In particular, the repeat coronary angiography after 9 months in the RCT study may have led to the detection of asymptomatic ISR and thus to a consequently higher rate of TVR. Finally, it remains unknown if routine use of intravascular imaging, namely OCT, would have influenced the outcomes of our ISR cohort and their management. Consequently, scaffold sizing may have been 'less precise' among parts of the study population.

In conclusion, treatment of ISR in a high-risk population using the everolimus-eluting BRS Absorb resulted in a near linear increase of DOCE between 1 year and 5 years after scaffold implantation. Considering our experience and the high rate of adverse events, with respect to the complexity of ISR involving also an unpredictable vascular healing process, current and future BRS should be used very restrictively for this indication.

Contributors MM and GMC: conceptualisation; data curation; methodology; writing-original draft. AA-T: conceptualisation; writing-original draft. MW: writingoriginal draft. FM: writing-original draft. TS: writing-original draft. LV: writing- 
original draft. PB: writing-original draft. ST: supervision; validation. RK: supervision; validation. MB: conceptualisation; supervision; validation; visualisation. FC: conceptualisation; supervision; validation; visualisation

Funding The authors have not declared a specific grant for this research from any funding agency in the public, commercial or not-for-profit sectors.

Competing interests MM, GMC, AA-T, MW, FM, TS, LV, ST and RK report no conflicts of interest. MB has received consulting and speaker fees from Amgen, Astra Zeneca, Bayer and Mundipharma. FC has received consulting and speaker fees from SIS Medical and Abbott Vascular.

Patient consent for publication Not required

Provenance and peer review Not commissioned; externally peer reviewed.

Data availability statement All data relevant to the study are included in the article or uploaded as online supplemental information.

Open access This is an open access article distributed in accordance with the Creative Commons Attribution Non Commercial (CC BY-NC 4.0) license, which permits others to distribute, remix, adapt, build upon this work non-commercially, and license their derivative works on different terms, provided the original work is properly cited, appropriate credit is given, any changes made indicated, and the use is non-commercial. See: http://creativecommons.org/licenses/by-nc/4.0/.

ORCID iD

Mehdi Madanchi http://orcid.org/0000-0001-6366-6211

\section{REFERENCES}

1 Byrne RA, Sarafoff N, Kastrati A, et al. Drug-eluting stents in percutaneous coronary intervention: a benefit-risk assessment. Drug Saf 2009:32:749-70.

2 Morice M-C, Serruys PW, Sousa JE, et al. A randomized comparison of a sirolimus-eluting stent with a standard stent for coronary revascularization. N Engl J Med 2002;346:1773-80.

3 Cassese S, Byrne RA, Tada T, et al. Incidence and predictors of restenosis after coronary stenting in 10004 patients with surveillance angiography. Heart 2014;100:153-9.

4 Bønaa KH, Mannsverk J, Wiseth R, et al. Drug-eluting or bare-metal stents for coronary artery disease. N Engl J Med 2016;375:1242-52.

5 Alfonso F, Pérez-Vizcayno MJ, Cárdenas A, et al. Rationale and design of the RIBS IV randomised clinical trial (drug-eluting balloons versus everolimus-eluting stents for patients with drug-eluting stent restenosis). Eurolntervention 2015;11:336-42.

6 Lemos PA, Hoye A, Goedhart D, et al. Clinical, angiographic, and procedural predictors of angiographic restenosis after sirolimuseluting stent implantation in complex patients: an evaluation from the Rapamycin-Eluting Stent Evaluated At Rotterdam Cardiology Hospital (RESEARCH) study. Circulation 2004;109:1366-70.

7 Neumann F-J, Sousa-Uva M, Ahlsson A, et al. [2018 ESC/EACTS Guidelines on myocardial revascularization. The Task Force on myocardial revascularization of the European Society of Cardiology (ESC) and European Association for Cardio-Thoracic Surgery (EACTS)]. G Ital Cardiol 2019;20:1S-61.

8 Giacoppo D, Alfonso F, Xu B, et al. Drug-coated balloon angioplasty versus drug-eluting stent implantation in patients with coronary stent restenosis. J Am Coll Cardiol 2020;75:2664-78.

9 Alfonso F, García J, Pérez-Vizcayno M-J, et al. New stent implantation for recurrences after stenting for in-stent restenosis: implications of a third metal layer in human coronary arteries. J Am Coll Cardiol 2009;54:1036-8.

10 Ellis SG, Kereiakes DJ, Metzger DC, et al. Everolimus-eluting bioresorbable scaffolds for coronary artery disease. $N$ Engl J Med 2015;373:1905-15.

11 Jamshidi P, Nyffenegger T, Sabti Z, et al. A novel approach to treat in-stent restenosis: 6- and 12-month results using the everolimus-eluting bioresorbable vascular scaffold. Eurolntervention 2016;11:1479-86.

12 Cuculi F, Bossard M, Zasada W, et al. Performing percutaneous coronary interventions with predilatation using non-compliant balloons at high-pressure versus conventional semi-compliant balloons: insights from two randomised studies using optical coherence tomography. Open Heart 2020;7:e001204.

13 Mehran R, Dangas G, Abizaid AS, et al. Angiographic patterns of in-stent restenosis: classification and implications for long-term outcome. Circulation 1999;100:1872-8.

14 Cutlip DE, Windecker S, Mehran R, et al. Clinical end points in coronary stent trials: a case for standardized definitions. Circulation 2007:115:2344-51.

15 Tamburino C, Latib A, van Geuns R-J, et al. Contemporary practice and technical aspects in coronary intervention with bioresorbable scaffolds: a European perspective. Eurolntervention 2015;11:45-52.

16 lqbal J, Onuma Y, Ormiston J, et al. Bioresorbable scaffolds: rationale, current status, challenges, and future. Eur Heart $J$ 2014;35:765-76.

17 Bossard M, Attinger A, Wolfrum M, et al. Bioresorbable scaffold versus drug coated balloon for treatment of in-stent-restenosis long-term outcomes of the randomized ABSORB-ISR trial. Eur Heart $J$ 2020;41.

18 Ota $\mathrm{H}$, Mahmoudi M, Kitabata $\mathrm{H}$, et al. Safety and efficacy of limuseluting stents and balloon angioplasty for sirolimus-eluting in-stent restenosis. Cardiovasc Revasc Med 2015;16:84-9.

19 Maluenda G, Ben-Dor I, Gaglia MA, et al. Clinical outcomes and treatment after drug-eluting stent failure: the absence of traditional risk factors for in-stent restenosis. Circ Cardiovasc Interv 2012;5:12-19.

20 Yabushita H, Kawamoto H, Fujino Y, et al. Clinical outcomes of drug-eluting balloon for in-stent restenosis based on the number of metallic layers. Circ Cardiovasc Interv 2018;11:e005935.

21 Kereiakes DJ, Ellis SG, Metzger DC, et al. Clinical outcomes before and after complete everolimus-eluting Bioresorbable scaffold resorption: five-year follow-up from the ABSORB III trial. Circulation 2019;140:1895-903.

22 Wykrzykowska JJ, Kraak RP, Hofma SH, et al. Bioresorbable scaffolds versus metallic stents in routine PCl. N Engl J Med 2017;376:2319-28.

23 lantorno M, Lipinski MJ, Garcia-Garcia HM, et al. Meta-Analysis of the impact of strut thickness on outcomes in patients with drug-eluting stents in a coronary artery. Am J Cardiol 2018;122:1652-60.

24 Forrestal B, Case BC, Yerasi C, et al. Bioresorbable scaffolds: current technology and future perspectives. Rambam Maimonides Med J 2020;11. doi:10.5041/RMMJ.10402. [Epub ahead of print: 29 04 2020].

25 Bangalore S, Bezerra HG, Rizik DG, et al. The State of the Absorb Bioresorbable Scaffold: Consensus From an Expert Panel. JACC Cardiovasc Interv 2017;10:2349-59.

26 Foin N, Lee RD, Torii R, et al. Impact of stent strut design in metallic stents and biodegradable scaffolds. Int J Cardiol 2014;177:800-8.

27 Sakamoto A, Jinnouchi H, Torii S, et al. Understanding the impact of stent and scaffold material and strut design on coronary artery thrombosis from the basic and clinical points of view. Bioengineering 2018;5. doi:10.3390/bioengineering5030071. [Epub ahead of print: 0409 2018].

28 Koppara T, Cheng Q, Yahagi K, et al. Thrombogenicity and early vascular healing response in metallic biodegradable polymer-based and fully bioabsorbable drug-eluting stents. Circ Cardiovasc Interv 2015;8:e002427.

29 Stone GW, Gao R, Kimura T, et al. 1-year outcomes with the absorb bioresorbable scaffold in patients with coronary artery disease: a patient-level, pooled meta-analysis. Lancet 2016;387:1277-89.

30 Kereiakes DJ, Ellis SG, Metzger C, et al. 3-year clinical outcomes with everolimus-eluting bioresorbable coronary scaffolds: the ABSORB III trial. J Am Coll Cardiol 2017;70:2852-62.

31 Azzalini L, Ellis SG, Kereiakes DJ, Lorenzo A, Stephen GE, Dean JK, et al. Optimal dual antiplatelet therapy duration for Bioresorbable scaffolds: an individual patient data pooled analysis of the absorb trials. Eurolntervention 2021. doi:10.4244/EIJ-D-21-00263. [Epub ahead of print: 0806 2021]

32 Mukherjee D. Device thrombosis with Bioresorbable scaffolds. N Engl J Med Overseas Ed 2017;376:2388-9. 